\title{
Asthma self-management skills and the use of asthma education during pregnancy
}

\author{
V.E. Murphy*, P.G. Gibson*, P.I. Talbot ${ }^{\#}$, C.G. Kessell* and V.L. Clifton ${ }^{\#}$
}

ABSTRACT: During pregnancy, patients with asthma are at risk of poor outcomes, particularly when asthma is poorly controlled. The aim of this study was to determine the level of asthma selfmanagement skills and knowledge among pregnant subjects and describe the implementation of an asthma education programme delivered in an antenatal clinic setting.

Pregnant subjects with asthma were assessed by an asthma educator at $20(n=211)$ and 33 weeks gestation $(n=149)$. Lung function, symptoms, medication use, adherence, knowledge and inhaler technique were assessed. They were asked whether they had a written asthma action plan, or performed peak flow monitoring. Asthma was classified as mild, moderate or severe.

At the first visit with the asthma educator, $40 \%$ of females reported nonadherence to inhaled corticosteroids, inhaler technique was assessed as inadequate in $16 \%$ and $42 \%$ had inadequate medication knowledge. Peak flow monitoring was performed by $3 \%$ and $15 \%$ had a written action plan. There were significant improvements in all aspects of asthma self-management following education. In females with severe asthma, night symptoms and reliever medication use significantly decreased after education.

In conclusion, during pregnancy, patients with asthma have poor asthma knowledge and skills, and may benefit from self-management education as part of their obstetric care.

KEYWORDS: Action plan, asthma, pregnancy, self-management education

A sthma is the most common respiratory disorder to complicate pregnancy, leading to significant morbidity for both mother and foetus in the form of low birth weight [1, 2], pre-term delivery [1, 2], preeclampsia [3,4] and worsening asthma in the mother [5]. Asthmatics who experience moderateto-severe symptoms [4] or acute episodes of asthma during pregnancy [6] are at particular risk of poor outcomes. Asthmatic females may benefit from closer monitoring of their asthma during pregnancy, in order to ensure optimum treatment and control during this period. Asthma education is a novel way of approaching asthma care in the obstetric population, which may lead to improved outcomes for both mother and child.

Asthma self-management education programmes are an important component of asthma management and have been found to be effective in nonpregnant adults $[7,8]$. Successful programmes incorporate education, self-monitoring, regular review with optimisation of pharmacotherapy and a written plan for the management of unstable asthma $[7,8]$. Although recommended in asthma guidelines, no studies have reported the use of asthma education programmes for pregnant subjects and the success of self-management education during pregnancy remains unknown.

The aim of the present study was to assess asthma self-management skills and knowledge in a group of pregnant subjects with mild, moderate and severe asthma who were recruited to a research study investigating the effects of asthma on placental function and foetal growth [9-12], and to determine the need for improved selfmanagement during pregnancy.

\section{MATERIALS AND METHODS}

Approval for the study was provided by the Hunter Area Health Service and University of Newcastle Human Research Ethics Committees (both NSW, Australia). Written informed consent was given for participation. Pregnant subjects with a doctor diagnosis of asthma $(n=211)$ were recruited through the John Hunter Hospital antenatal clinics (NSW, Australia) and assessed by a nurse with specific training in asthma education [13] (the asthma educator) at $\sim 20$ weeks gestation. This was termed the first visit, indicating the first time they were assessed by the asthma educator. A follow-up assessment occurred in 149 females at $\sim 33$ weeks gestation (last visit). The same asthma educator saw
AFFILIATIONS

*Dept of Respiratory and Sleep

Medicine, and

\#Mothers and Babies Research Centre, Hunter Medical Research Institute, University of Newcastle, Australia.

CORRESPONDENCE

V. Clifton

Mothers and Babies Research Centre Endocrine Unit

John Hunter Hospital

Locked Bag 1

Hunter Region Mail Centre

Newcastle

New South Wales

2310

Australia

Fax: 61249214394

E-mail: vicki.clifton@newcastle.

edu.au

Received:

November 282004

Accepted after revision:

June 022005

\section{SUPPORT STATEMENT}

This study was supported by the National Health and Medical Research Council (ID 252438), Asthma Foundation of New South Wales, Hunter Medical Research Institute and New South Wales Health. V. Murphy was the recipient of a National Health and Medical Research Council (NHMRC) Dora Lush (Biomedical) Postgraduate Scholarship and a Hunter Medical Research Institute/Port Waratah Coal Services Postdoctoral Fellowship. V. Clifton was the recipient of the Arthur Wilson Memorial Scholarship from the Royal Australian College of Obstetricians and Gynaecologists and a NHMRC Career Development Grant (ID 300786). P. Gibson is an NHMRC Practitioner Fellow. 
patients for all of their visits. Foetal sex and birth weight were determined after delivery. This group of asthmatic females was recruited as part of an ongoing, prospective, cohort study. Maternal characteristics, maternal corticosteroid use and placental and foetal outcomes have previously been reported for some of these subjects [9-12].

Each visit consisted of a 30-60 min session where a history of asthma, including medication use, was taken. The asthma management skills assessed were: medication adherence (inhaled corticosteroid (ICS) users only) and knowledge, inhaler device technique, possession of a written action plan and self-monitoring [13]. The assessment of adherence followed a review of the medications which the patient had been using in the previous week. Nonadherence was assessed in a nonjudgemental and nonthreatening manner by asking: "It can be difficult to remember all of your medicines when things get busy. How many times in the past week have you missed a dose of your preventer?" Patients were considered adherent if they took $80 \%$ of their prescribed doses. Medication knowledge was rated as adequate or inadequate following direct questioning of patients regarding how the reliever and preventer medications work, and specific situations in which a particular inhaler would be used. Inhaler technique was demonstrated by the patient using their own inhaler or placebo and assessed according to the presence of the following criteria: 1) shake inhaler; 2) hold correctly; 3) actuate once only; 4) actuate on inspiration; 5) continue inspiration after actuation; 6) hold breath $\geqslant 3 \mathrm{~s}$; 7) slow inspiration; and 8) deep inspiration. Inhaler technique was rated as: optimal if all criteria were met; adequate when the first five criteria were met; and inadequate if any one of the first five criteria were not met. Patients were asked whether they currently had a written action plan (clarified as meaning written instructions on what to do when asthma gets worse and how to recognise when asthma gets worse) and if they performed peak expiratory flow (PEF) monitoring.

Asthma control was assessed by direct questioning of how many days in the past week the patient had been affected by night-time symptoms, morning symptoms or activity limitation due to asthma and the frequency of $\beta_{2}$-agonist (reliever medication) use. Forced expiratory volume at one second (FEV1) and forced vital capacity were measured by spirometry in some subjects (Vitalograph, Buckingham, UK). FEV1 \% predicted was calculated based on the patient's age and height using the equations of KNUDSON et al. [14].

Study participants received education about asthma control and management skills, including trigger avoidance and smoking cessation counselling where appropriate. Patients were offered two visits, with additional visits available if required. Patients assessed as unstable and requiring medical review were referred to their primary care physician or to a respiratory physician. Urgent medical review was available for patients with an acute exacerbation. Some subjects were provided with a written action plan, which was developed according to evidence based principles [8] by the asthma educator using a standardised template. The supervising physician reviewed each action plan and a written copy was given to the patient and posted to the primary care physician.
Asthma severity was classified as mild, moderate or severe according to symptoms, asthma history and other features including FEV1 and PEF $[15,16]$. Females were assigned to the most severe category which applied for any one of these criteria. Characteristics of mild asthma were: FEV1 $>80 \%$ pred; $<25 \%$ PEF diurnal variability; no night-time or morning symptoms; infrequent $\beta_{2}$-agonist use; daytime symptoms less then four times per week and no severe attacks in the previous year. Characteristics of moderate asthma were: FEV1 60-80\% pred; $<25 \%$ PEF diurnal variability; night-time symptoms once per week; $\beta_{2}$-agonist use and daytime symptoms most days. Characteristics of severe asthma were: FEV1 $<60 \%$ pred; $>25 \%$ PEF diurnal variability; frequent night-time symptoms; daily morning and daytime symptoms; $\beta_{2}$-agonist use three to four times per day and limited physical activity. Most females used ICS (budesonide, beclomethasone dipropionate or fluticasone propionate). Oral steroid (prednisone) was used periodically by a small number of patients. All subjects used the $\beta_{2}$-agonist, salbutamol for symptom relief when required.

Results are presented as median (interquartile range) for nonparametric data or mean $\pm \mathrm{SE}$ of the mean for parametric data. Analysis of variance (ANOVA) and the nonparametric equivalent (Kruskal-Wallis test) were used with the appropriate post hoc test (Tukey-Kramer multiple comparisons test or Dunn's multiple comparisons test). When comparing two groups, the unpaired t-test or Mann-Whitney U-test was used. Fisher's exact test was used to compare proportions. A p-value $<0.05$ was considered significant.

\section{RESULTS}

\section{Subject characteristics}

Table 1 shows the characteristics for subjects with mild $(n=108)$, moderate $(n=42)$ and severe $(n=61)$ asthma. There were no significant differences between the groups for gestational age at first visit, maternal age, weight (KruskalWallis test: $p>0.05)$, height and weight gain during pregnancy (ANOVA: $p>0.05$ ) or proportion of current smokers (Fisher's exact test: $\mathrm{p}>0.05)$. Gravidity and parity were significantly higher in females with severe asthma compared with females with mild asthma (Kruskal Wallis test and Dunn's multiple comparisons test: $\mathrm{p}<0.05)$. The percentage of patients using ICS was significantly lower in females with mild asthma compared with moderate and severe asthma (Fisher's exact test: $\mathrm{p}<0.0001)$.

\section{Inhaled corticosteroid use}

Females with mild asthma used significantly less ICS in all trimesters compared with moderate and severe asthmatics (table 2; Kruskal-Wallis test and Dunn's multiple comparisons test: $\mathrm{p}<0.05)$. The ICS dose significantly increased from first to third trimester in females with moderate and severe asthma (non-parametric repeated measures ANOVA and Dunn's multiple comparisons test: $<0.05$ and $\mathrm{p}<0.001$, respectively).

\section{Self-management skills at the first visit}

At their first visit, pregnant asthmatic subjects had poor selfmanagement skills and knowledge. Overall, 40\% of females reported nonadherence to ICS medication, inhaler technique was inadequate in $16 \%, 42 \%$ had poor knowledge about asthma medications and 3\% were performing regular peak 
TABLE 1 Subject characteristics

\begin{tabular}{|c|c|c|c|c|c|c|}
\hline & \multicolumn{2}{|c|}{ Mild asthma } & \multicolumn{2}{|c|}{ Moderate asthma } & \multicolumn{2}{|c|}{ Severe asthma } \\
\hline & Subjects $\mathrm{n}$ & Data & Subjects $\mathrm{n}$ & Data & Subjects $n$ & Data \\
\hline Gestational age at first visit weeks & 108 & $23(18-30)$ & 42 & $20(17-30)$ & 61 & $22(18-28)$ \\
\hline Maternal age yrs & 108 & $23(22-29)$ & 42 & $28(22-33)$ & 61 & $27(22-29)$ \\
\hline Maternal height $\mathbf{c m}$ & 102 & $163.4 \pm 0.7$ & 41 & $163.4 \pm 1.0$ & 57 & $165.2 \pm 0.8$ \\
\hline Gravidity & 108 & $2(1-3)$ & 42 & $2(1-3)$ & 60 & $3(1-4)^{\#}$ \\
\hline Parity & 108 & $0(0-1)$ & 42 & $1(0-1)$ & 60 & $1(0-2)^{\#}$ \\
\hline Using inhaled corticosteroids \% & & $42^{\circ}$ & & 79 & & 87 \\
\hline Using periodic oral corticosteroids \% & & 0 & & $10^{+}$ & & $27^{\S}$ \\
\hline Current smokers \% & & 23 & & 33 & & 28 \\
\hline
\end{tabular}

\section{TABLE 2 Inhaled corticosteroid use during pregnancy}

Mild asthma Moderate asthma Severe asthma

\begin{tabular}{|c|c|c|c|}
\hline Subjects n & 108 & 42 & 61 \\
\hline First trimester $\mu \mathrm{g} / \mathrm{day}$ & $0(0-400)^{\#}$ & $375(0-1000)$ & $400(0-1000)$ \\
\hline Second trimester $\mu \mathrm{g} / \mathrm{day}$ & $0(0-450)^{\#}$ & $775(0-1000)$ & $1000(0-1500)$ \\
\hline Third trimester $\mu \mathrm{g} / \mathrm{day}$ & $0(0-500)^{\#}$ & $800(250-1000)^{\circ}$ & $1000(450-1600)^{\bullet}$ \\
\hline $\begin{array}{c}\text { Average pregnancy } \\
\text { intake } \mu \mathrm{g} / \text { day }\end{array}$ & $0(0-450)^{\#}$ & $667(133-1000)$ & $667(267-1167)$ \\
\hline
\end{tabular}

Data are presented as median (interquartile range). ${ }^{*}$ : compared with moderate and severe asthma (Kruskal-Wallis test and Dunn's multiple comparisons test: $\mathrm{p}<0.05$ ); ": compared with first trimester (non-parametric repeated measures analysis of variance and Dunn's multiple comparisons test: $p<0.05$ ).

flow monitoring. Only $15 \%$ of the asthmatic females had a written action plan.

\section{Influence of asthma severity on self-management skills at the first visit}

In females who used ICS, the rate of medication nonadherence was $31 \%$ in the mild asthma group, which was not different from the moderate $(46 \%)$ or severe asthma groups $(45 \%$; fig. 1a; Fisher's exact test: $\mathrm{p}>0.05)$. Significantly more mild asthmatics had inadequate inhaler technique $(23 \%)$ compared with moderate $(11 \%)$ or severe $(9 \%)$ asthmatics (fig. 1a; Fisher's exact test: $\mathrm{p}<0.05)$. Medication knowledge was similar among the mild, moderate and severe groups $(53,69$ and 58\%, respectively). The percentage of patients with a written action plan was not different between groups (14, 8 and $22 \%$ in mild, moderate and severe asthma groups, respectively) and few patients were conducting peak flow monitoring $(1,0$ and $9 \%$ in mild, moderate and severe asthma groups, respectively; Fisher's exact test: $\mathrm{p}>0.05$; fig. 1a).

\section{Self-management skills after asthma education}

In total, $64 \%$ of mild, $83 \%$ of moderate and $74 \%$ of severe asthmatics attended at least two visits with the asthma educator. The 62 patients who were not followed declined to participate further in the study. Patients who were followedup were not significantly different from those who were not followed in terms of age, height, weight gain, gravidity, parity (Mann-Whitney U-test or unpaired t-test: $\mathrm{p}>0.05$ ), smoking or use of ICS or oral corticosteroids during pregnancy (Fisher's exact test; $\mathrm{p}>0.05$; data not shown).

After asthma education, there was an improvement in selfmanagement skills in asthmatic females. Self-reported nonadherence to ICS decreased from $40-21 \%$ (Fisher's exact test: $p=0.006$ ), inadequate inhaler technique decreased from $16-4 \%$ (Fisher's exact test: $\mathrm{p}=0.005$ ) and adequate medications knowledge improved from $58-95 \%$ of subjects (Fisher's exact test: $\mathrm{p}<0.0001)$. The percentage of subjects conducting peak flow monitoring increased from 3-35\% (Fisher's exact test: $\mathrm{p}<0.0001$ ) and possession of an action plan increased from 15$75 \%$ of all asthmatic females (Fisher's exact test: $<0.0001$ ).

\section{Influence of asthma severity on self-management skills after asthma education}

Among females with severe asthma, there was a significant fall in the percentage of patients who were nonadherent to ICS medication after education (fig. $1 \mathrm{~b}$; Fisher's exact test: $p=0.014$ ). In mild asthmatics, there was a significant decrease in the number of patients with inadequate inhaler technique after education (fig. 1b; Fisher's exact test: $\mathrm{p}=0.006$ ).

Among mild, moderate and severe asthmatics there were significant increases in the proportion of patients with adequate medication knowledge, an asthma action plan and the proportion conducting peak flow monitoring after asthma education (fig. 1b; Fisher's exact test: $\mathrm{p}<0.05$ ). Significantly more severe asthmatics were monitoring peak flow compared with moderate asthmatics (Fisher's exact test: $p=0.016$ ). 

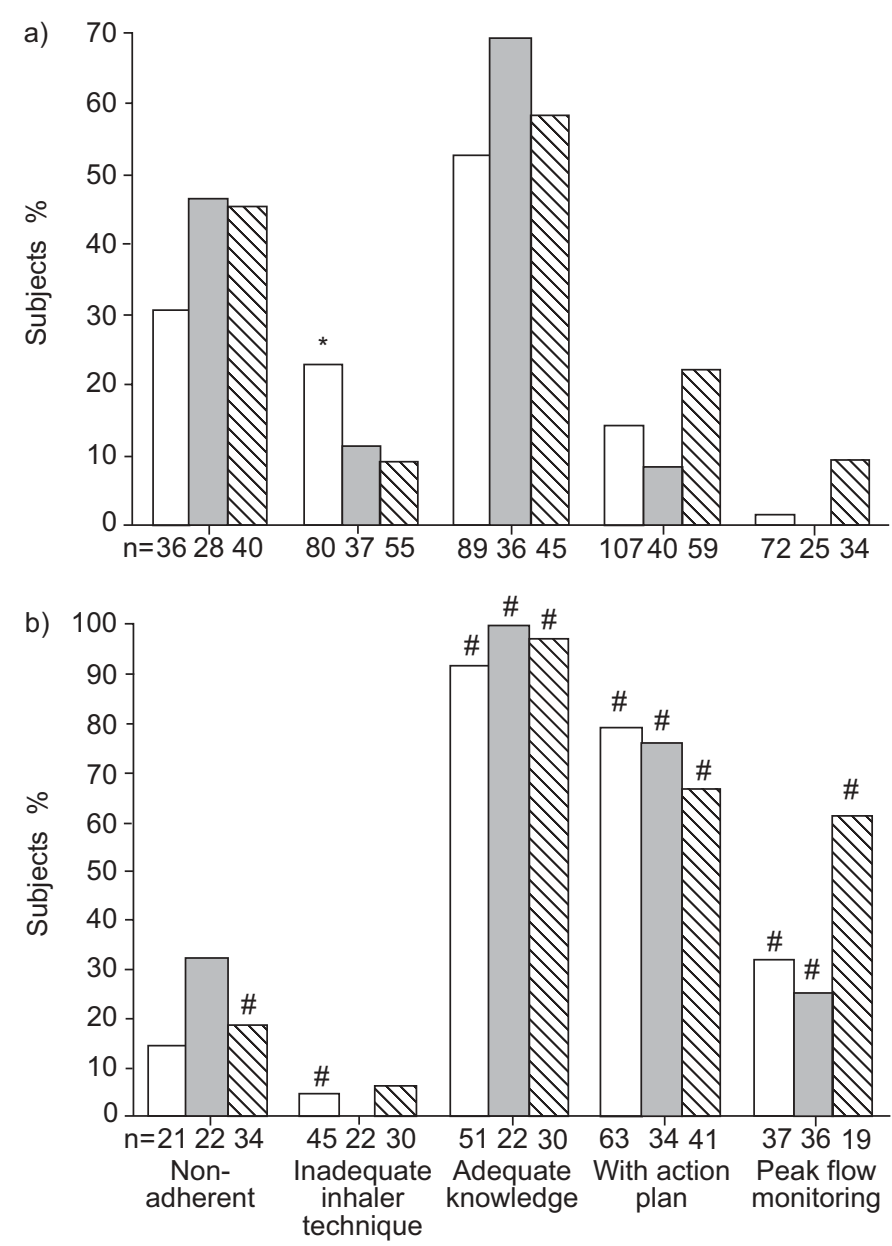

FIGURE 1. Asthma self-management skills of pregnant subjects with mild, moderate and severe asthma. The percentage of patients within mild $(\square)$, moderate $(\square)$ and severe $(\mathbb{\$})$ asthma groups who were nonadherent (inhaled corticosteroid medication), had inadequate inhaler technique, adequate medications knowledge, a written action plan and performed peak flow monitoring at a) first visit, and b) last visit. *: $p<0.05$ (Fisher's exact test; mild versus moderate and severe); $\#$ : $p<0.05$ (Fisher's exact test compared with first visit).

\section{Lung function, symptoms and reliever medication use}

There were no differences in lung function (unpaired t-test: $\mathrm{p}>0.05$ ), symptom reporting or reliever medication use (MannWhitney U-test: $\mathrm{p}>0.05$ ) between the first and last visit for the mild, moderate or severe asthmatics (tables 3-5). In females with severe asthma there was a significant reduction in the number of night-time symptoms (table 5; Mann-Whitney Utest: $\mathrm{p}<0.0001)$ and in reliever medication use by the last visit (table 5; Mann-Whitney U-test: $\mathrm{p}<0.02$ ).

\section{Asthma action plans and birth weight}

Females who received an action plan had neonates with higher birth weight (Mann-Whitney U-test: $\mathrm{p}>0.05$ ). During pregnancies complicated by moderate and severe asthma, female birth weight was significantly lower in those without an action plan $(3101 \pm 112 ; n=29)$, compared with those with an action plan $(3481 \pm 143 ; n=17$; unpaired t-test: $\mathrm{p}=0.043)$, while male birth weight was unaffected $(3446 \pm 84 ; \mathrm{n}=33$ with action plan versus $3443 \pm 143 ; n=19$ no action plan; unpaired t-test: $\mathrm{p}>0.05$ ).

\begin{tabular}{|c|c|c|c|c|}
\hline \multirow[t]{3}{*}{ TABLE 3} & $\begin{array}{l}\text { ges in lung } \\
\text { cation use } \\
\text { cts with mi }\end{array}$ & $\begin{array}{l}\text { function, } \\
\text { rom first tc } \\
\text { d asthma }\end{array}$ & $\begin{array}{l}\text { mptoms an } \\
\text { ast visit in }\end{array}$ & $\begin{array}{l}\text { d reliever } \\
\text { oregnant }\end{array}$ \\
\hline & \multicolumn{2}{|c|}{ First visit } & \multicolumn{2}{|c|}{ Last visit } \\
\hline & Subjects $n$ & Data & Subjects $n$ & Data \\
\hline $\begin{array}{l}\text { Gestational age } \\
\text { weeks }\end{array}$ & 108 & $23(18-30)$ & 69 & $34(30-36)$ \\
\hline Maternal FEV 1 L & 89 & $3.14 \pm 0.05$ & 41 & $3.13 \pm 0.08$ \\
\hline $\begin{array}{l}\text { Maternal FEV1 } \\
\% \text { pred }\end{array}$ & 86 & $102 \pm 2$ & 40 & $102 \pm 2$ \\
\hline Maternal FVC L & 89 & $3.79 \pm 0.06$ & 41 & $3.83 \pm 0.09$ \\
\hline Maternal FEV1:FVC & 89 & $0.83 \pm 0.01$ & 41 & $0.82 \pm 0.01$ \\
\hline $\begin{array}{l}\text { Night symptoms } \\
\text { days } \cdot \text { week }^{-1}\end{array}$ & 108 & $0(0-0)$ & 69 & $0(0-0)$ \\
\hline 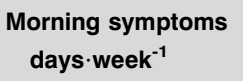 & 108 & $0(0-0)$ & 69 & $0(0-0)$ \\
\hline 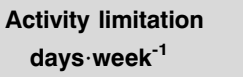 & 108 & $0(0-0)$ & 69 & $0(0-0)$ \\
\hline 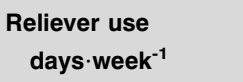 & 107 & $0(0-2)$ & 69 & $0(0-3)$ \\
\hline $\begin{array}{l}\text { Reliever use } \\
\text { times } \cdot \text { day }^{-1}\end{array}$ & 107 & $0(0-1)$ & 69 & $0(0-1)$ \\
\hline 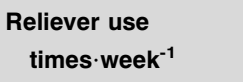 & 17 & $0(0-2)$ & 69 & $0(0-3)$ \\
\hline
\end{tabular}

\section{DISCUSSION}

The present study demonstrated that pregnant subjects with asthma have poor asthma self-management skills and knowledge, regardless of the severity of their asthma. Overall, $40 \%$ of patients were nonadherent with ICS medication, $<50 \%$ had optimal inhaler technique and $42 \%$ had inadequate knowledge about their prescribed medications. ICS nonadherence is a particular problem in pregnancy, as many females have misconceptions regarding the safety of these drugs in pregnancy $[17,18]$. However, it has been demonstrated that a severe asthma attack presents more of a risk than the use of asthma medications due to the potential for a reduction in the supply of oxygen to the foetus $[19,20]$ and clinical guidelines emphasise that pregnant subjects should receive similar advice regarding medication use as nonpregnant subjects with asthma [21]. A survey of asthmatic females found that $40 \%$ valued the opinion of their obstetrician regarding asthma medication use during pregnancy [18]. Receiving education about their asthma in the setting of the antenatal clinic may give females more confidence that they can use their preventative asthma medication safely during pregnancy.

There is an expressed need for education and improved asthma management skills by females. Many pregnant subjects have concerns about the effect their asthma may have on the foetus and many would like more medical care, support and education [17, 18]. A survey of 501 asthmatic females of childbearing age reported that $82 \%$ of females who used ICS were concerned about their effects on the foetus as well as the 


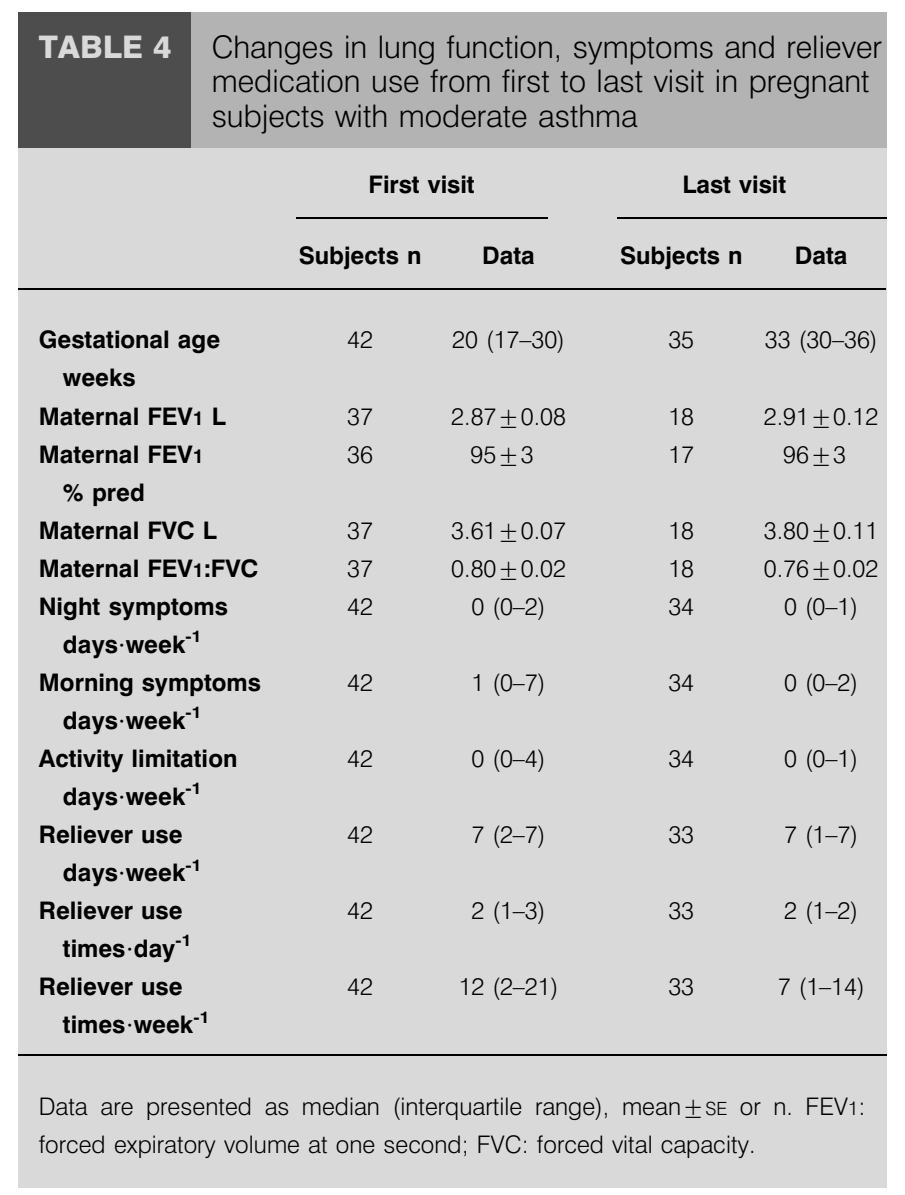

consequences of discontinuing medication on their own health [18]. Despite this, 39\% had discontinued medication while pregnant, without consultation with their physician [18]. Cessation of ICS therapy together with poor management skills could lead to significant deterioration in asthma control during pregnancy. The present data quantifies significant deficiencies in asthma self-management skills among these females and the current authors suggest that knowledge and skills may be greatly improved by a specific asthma education programme.

There is a strong link between asthma which is poorly controlled leading to hospitalisation and adverse perinatal outcomes [22, 23]. Programmes which improve asthma control and medication adherence could, therefore, be of benefit to both mother and foetus. Asthma self-management education is associated with significant improvements in healthcare utilisation, especially in hospital-based programmes [7]. The current study adapted an asthma education programme to an antenatal clinic setting. This presented its own challenges, including brief consultation times, patient needs, fitting in with the structure of the clinic and encouraging staff to see the value of asthma education during pregnancy. In addition, the asthma educator needed to be flexible to accommodate patient and clinic demands and access to a respiratory specialist or primary care physician was required for patients needing alterations to their asthma medications. Despite these challenges, the data indicate that there are likely to be clinical benefits for both mother and

\begin{tabular}{|c|c|c|c|c|c|}
\hline \multirow{3}{*}{\multicolumn{2}{|c|}{ TABLE 5}} & \multicolumn{4}{|c|}{$\begin{array}{l}\text { Changes in lung function, symptoms and reliever } \\
\text { medication use from first to last visit in pregnant } \\
\text { subjects with severe asthma }\end{array}$} \\
\hline & & \multicolumn{2}{|c|}{ First visit } & \multicolumn{2}{|c|}{ Last visit } \\
\hline & & Subjects $n$ & Data & Subjects $n$ & Data \\
\hline \multicolumn{2}{|c|}{$\begin{array}{l}\text { Gestational age } \\
\text { weeks }\end{array}$} & 61 & $22(18-28)$ & 45 & $32(30-35)$ \\
\hline \multicolumn{2}{|c|}{ Maternal FEV 1 L } & 46 & $2.87 \pm 0.09$ & 22 & $2.95 \pm 0.10$ \\
\hline \multicolumn{2}{|c|}{$\begin{array}{l}\text { Maternal FEV } 1 \\
\% \text { pred }\end{array}$} & 42 & $91 \pm 3$ & 22 & $95 \pm 3$ \\
\hline \multicolumn{2}{|c|}{ Maternal FVC L } & 46 & $3.57 \pm 0.09$ & 22 & $3.68 \pm 0.11$ \\
\hline \multicolumn{2}{|c|}{ Maternal FEV1:FVC } & 46 & $0.80 \pm 0.01$ & 22 & $0.80 \pm 0.02$ \\
\hline \multicolumn{2}{|c|}{$\begin{array}{l}\text { Night symptoms } \\
\text { days } \cdot \text { week }^{-1}\end{array}$} & 61 & $5(2-7)$ & 45 & $0(0-3)^{\#}$ \\
\hline \multicolumn{2}{|c|}{ 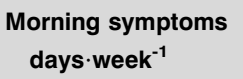 } & 61 & $4(0-7)$ & 45 & $2(0-7)$ \\
\hline \multicolumn{2}{|c|}{ 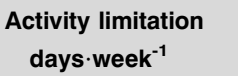 } & 61 & $1(0-5)$ & 44 & $0(0-6)$ \\
\hline \multicolumn{2}{|l|}{$\begin{array}{l}\text { Reliever use } \\
\text { days } \cdot \text { week }^{-1}\end{array}$} & 61 & $7(7-7)$ & 45 & $7(2-7)^{\#}$ \\
\hline \multicolumn{2}{|l|}{$\begin{array}{r}\text { Reliever use } \\
\text { times } \cdot \text { day }^{1}\end{array}$} & 61 & $3(2-5)$ & 45 & $2(1-3)^{\#}$ \\
\hline \multicolumn{2}{|c|}{$\begin{array}{l}\text { Reliever use } \\
\text { times' } \text { week }^{-1}\end{array}$} & 61 & $21(7-35)$ & 45 & $7(3-14)^{\#}$ \\
\hline
\end{tabular}

Data are presented as median (interquartile range), mean \pm SE or $n$. FEV1: forced expiratory volume at one second; FVC: forced vital capacity. \#: compared with first visit (Mann-Whitney U-test; $p<0.05$ ).

child from an asthma education programme in this setting. The present authors believe that integrating asthma education with routine antenatal care will increase the participation rate, which is a recognised problem in asthma education programmes [24]. This model also integrates well with a shared care system, where asthma education occurs as part of the antenatal visits with communication with the primary care physician.

Although there are deficiencies in study design, the analysis indicated a significant improvement in asthma selfmanagement skills following the implementation of the education programme. The lack of a comparison group of pregnant asthmatic subjects who did not receive asthma education makes interpretation of the present findings difficult. The time which elapsed between the two education visits was $\sim 3$ months and changes in skills and asthma control may have been confounded by the stage of pregnancy and other factors associated with asthma such as season of the year. From the literature, one third of asthmatic females would be expected to experience a subjective improvement during pregnancy [25] and these females may have biased the results. Nonetheless, this study is the first to demonstrate the potential of asthma education delivered in the antenatal clinic to provide patients with the skills and knowledge they require for selfmanagement. Future studies should address the level of education which is required to provide a clinical benefit for mother and child. 
While the benefits of self-management education on asthma control could only be measured in females with severe asthma, improvements in self-management skills occurred in females with mild, moderate and severe asthma. By the end of the study, only $21 \%$ of subjects were reporting nonadherence to ICS medication and among severe asthmatics there was a significant improvement in adherence. The same asthma educator saw the patients at both of their visits and was not blinded. There may have been some bias towards patients answering positively to these questions at the last visit. However, previous studies support improved medication adherence with education [26]. At the last visit, inhaler technique was inadequate in only $4 \%$ of pregnant subjects as assessed by eight objective criteria. A previous study found that $38 \%$ of female adult patients demonstrated correct inhaler technique and $57 \%$ could provide accurate reasons for the use of different medications [27]. At the last visit it was found that, $95 \%$ of women had adequate medications knowledge, $35 \%$ were performing peak flow monitoring and $75 \%$ had a written asthma action plan.

Asthma is more likely to worsen during pregnancy in females with severe asthma [5]. The present study found a significant fall in nocturnal asthma symptoms as well as a significant reduction in $\beta_{2}$-agonist use from first to last visit in females with severe asthma. Despite the limitations of the before-after analysis, these results suggest that asthma education for pregnant subjects with severe asthma may lead to better asthma control. The lack of effect observed in mild and moderate asthma may be due to the lower levels of symptoms in these groups.

Since females with severe asthma are most likely to exacerbate and require an action plan, this should be a target group for self-management education in the future. Overall, only $15 \%$ of pregnant asthmatic females had a written action plan when they entered the current study. This is less than reported in some other Australian studies, which found that $30-35 \%$ of asthmatic adults had a written asthma management plan [28, 29]. However, the present data is similar to that reported by the Australian Centre for Asthma Monitoring (NSW, Australia) in 2003, which found that the proportion of females aged between $20-40$ yrs with a written action plan was $\leqslant 20 \%$ [30]. When subjects with moderate and severe asthma were examined, female birth weight was significantly higher in those who had an action plan compared with those who did not. The current authors have previously investigated the placental mechanisms leading to reduced foetal growth in asthmatic pregnancies [9-12] and have speculated that the female foetus is more sensitive to the underlying inflammation associated with maternal asthma, which may lead to changes in foetal growth through alterations in placental function [11]. The present data suggests that having knowledge about what to do when asthma worsens is an important skill which has the potential to lead to improved foetal outcome.

In conclusion, pregnant subjects with asthma have poor selfmanagement skills regardless of asthma severity, and the use of asthma education may improve outcomes for both the mother and their child. Self-management education is an important asthma management tool, which can be delivered in an antenatal clinic setting. Asthma education was associated with an increase in asthma medication knowledge, skills and adherence and the provision of a written asthma action plan was an essential component of the education programme. Asthma self-management education should be considered an important aspect of obstetric care.

\section{ACKNOWLEDGEMENTS}

The authors would like to thank the staff of the antenatal clinics at John Hunter Hospital (New South Wales, Australia) for assistance with patient recruitment.

\section{REFERENCES}

1 Kallen B, Rydhstroem H, Aberg A. Asthma during pregnancy-a population based study. Eur J Epidemiol 2000; 16: 167-171.

2 Liu S, Wen SW, Demissie K, Marcoux S, Kramer MS. Maternal asthma and pregnancy outcomes: a retrospective cohort study. Am J Obstet Gynecol 2001; 184: 90-96.

3 Stenius-Aarniala B, Piirila P, Teramo K. Asthma and pregnancy: a prospective study of 198 pregnancies. Thorax 1988; 43: 12-18.

4 Triche EW, Saftlas AF, Belanger K, Leaderer BP, Bracken MB. Association of asthma diagnosis, severity, symptoms, and treatment with risk of preeclampsia. Obstet Gynecol 2004; 104: 585-593.

5 Schatz M, Dombrowski MP, Wise R, et al. Asthma morbidity during pregnancy can be predicted by severity classification. J Allergy Clin Immunol 2003; 112: 283-288.

6 Stenius-Aarniala BS, Hedman J, Teramo KA. Acute asthma during pregnancy. Thorax 1996; 51: 411-414.

7 Gibson PG, Powell H, Coughlan J, et al. Self-management education and regular practitioner review for adults with asthma. Cochrane Database Syst Rev 2003; 1: CD001117.

8 Gibson PG, Powell H. Written action plans for asthma: an evidence-based review of the key components. Thorax 2004; 59: 94-99.

9 Clifton VL, Giles WB, Smith R, et al. Alterations of placental vascular function in asthmatic pregnancies. $A m$ J Respir Crit Care Med 2001; 164: 546-553.

10 Murphy VE, Zakar T, Smith R, Giles WB, Gibson PG, Clifton VL. Reduced 11beta-hydroxysteroid dehydrogenase type 2 activity is associated with decreased birth weight centile in pregnancies complicated by asthma. $J$ Clin Endocrinol Metab 2002; 87: 1660-1668.

11 Murphy VE, Gibson PG, Giles WB, et al. Maternal asthma is associated with reduced female fetal growth. Am J Respir Crit Care Med 2003; 168: 1317-1323.

12 Clifton VL, Murphy VE. Maternal asthma as a model for examining fetal sex-specific effects on maternal physiology and placental mechanisms that regulate human fetal growth. Placenta 2004; 25: Suppl. A, S45-S52.

13 Gibson PG, Wilson AJ. The use of continuous quality improvement methods to implement practice guidelines in asthma. J Qual Clin Pract 1996; 16: 87-102.

14 Knudson RJ, Slatin RC, Lebowitz MD, Burrows B. The maximal expiratory flow-volume curve. Normal standards, variability, and effects of age. Am Rev Respir Dis 1976; 113: 587-600.

15 National Asthma Campaign: Asthma management handbook. National Asthma Council Australia, Sydney, 1996. 
16 National Institute of Health: Guidelines for the diagnosis and management of asthma. Bethesda, MD, National Heart, Lung and Blood Institute, 1997.

17 Beckmann CA. A descriptive study of women's perceptions of their asthma during pregnancy. MCN Am J Matern Child Nurs 2002; 27: 98-102.

18 Chambers K. Asthma education and outcomes for women of childbearing age. Case Manager 2003; 14: 58-61.

19 McDonald CF, Burdon JG. Asthma in pregnancy and lactation. A position paper for the Thoracic Society of Australia and New Zealand. Med J Aust 1996; 165: 485-488.

20 Asthma Management Handbook. National Asthma Council Australia Ltd, South Melbourne, 2002.

21 National Heart Lungs and Blood Institute. Report of the working group on asthma and pregnancy. Executive summary: management of asthma during pregnancy. J Allergy Clin Immunol 1994; 93: 139-162.

22 Jana N, Vasishta K, Saha SC, Khunnu B. Effect of bronchial asthma on the course of pregnancy, labour and perinatal outcome. J Obstet Gynaecol 1995; 21: 227-232.

23 Sobande AA, Archibong EI, Akinola SE. Pregnancy outcome in asthmatic patients from high altitudes. Int $J$ Gynaecol Obstet 2002; 77: 117-121.

24 Abdulwadud O, Abramson M, Forbes A, et al. Attendance at an asthma educational intervention: characteristics of participants and non-participants. Respir Med 1997; 91: 524-529.
25 Schatz M, Harden K, Forsythe A, et al. The course of asthma during pregnancy, post partum, and with successive pregnancies: a prospective analysis. J Allergy Clin Immunol 1988; 81: 509-517.

26 Gallefoss F, Bakke PS. How does patient education and self-management among asthmatics and patients with chronic obstructive pulmonary disease affect medication? Am J Respir Crit Care Med 1999; 160: 2000-2005.

27 Pinto Pereira LM, Clement Y, Da Silva CK, McIntosh D, Simeon DT. Understanding and use of inhaler medication by asthmatics in specialty care in Trinidad: a study following development of Caribbean guidelines for asthma management and prevention. Chest 2002; 121: 1833-1840.

28 Ruffin RE, Wilson D, Southcott AM, Smith B, Adams RJ. A South Australian population survey of the ownership of asthma action plans. Med J Aust 1999; 171: 348-351.

29 Marks GB, Jalaludin BB, Williamson M, Atkin NL, Bauman A. Use of "preventer" medications and written asthma management plans among adults with asthma in New South Wales. NSW Health Department Asthma Data Working Group. Med J Aust 2000; 173: 407-410.

30 Australian Centre for Asthma Monitoring. Asthma in Australia 2003. AIHW Asthma Series 1. AIHW Cat. no. ACM1. Canberra, Australian Institute of Health and Welfare, 2003. 